\title{
Gonad dose in AP pelvis radiography: impact of anode heel orientation
}

\section{ABSTRACT}

Purpose: For antero posterior (AP) pelvis radiographic examination, determine the impact of anode heel orientation on female / male gonad dose.

Methods: High sensitivity thermo-luminescent dosimeters (TLDs) were used with an ATOM dosimetry phantom; the phantom was positioned for AP pelvis. TLDs were placed into the testes and ovaries. Radiation dose received by these organs was measured with the feet toward anode and feet toward the cathode. $\mathrm{kVp}, \mathrm{mAs}$ and SID were manipulated to generate a range of exposures. A dose profile was also generated using Unfors Mult-O-Meter 401 along the long axis of the phantom.

Results: A decrease in dose from the central ray toward the anode was noted, with a marked increase toward the cathode. A significant reduction in dose was received by the testes with feet towards the anode compared with feet towards cathode $(P<0.001)$. No difference was seen for ovarian dose $(P>0.05)$. kVp, mAs and SID all have an effect on male and female gonad dose.

Conclusion: For male pelvis imaging, placing feet towards the anode can be used as a simple dose reduction method.

Key words: Gonad dose, patient dosimetry, x-ray imaging 


\section{Introduction}

In radiography the primary goal of radiation protection is to optimise dose and image quality and a range of approaches exist to achieve this. Options include manipulating primary acquisition factors (e.g. kVp \& mAs), changing distance between skin and X-ray tube, using more efficient imaging detectors and using appropriate collimation and filtration (1). The impact of anode heel orientation on x-ray beam intensity has been described previously, with the percentage difference in beam intensity between anode and cathode ends varying by approximately $45 \%$ (2). Benefitting from this discrepancy the anode heel effect has been used advantageously for imaging non-uniform anatomical structures, such as femur and spine, in order to improve image quality (3-6). Few publications (two) have explored the impact of x-ray tube orientation on patient dose. One example is Fung and Gilboy (3) who evaluated how anode and cathode orientation impacts on gonad dose for AP and lateral lumbar spine radiography.

Our paper builds on the work of Fung and Gilboy (3) in order to determine whether anode / cathode orientation has any impact on male / female gonad dose for AP pelvis radiography. Antero posterior (AP) pelvis was selected because it is the third highest contributor of radiation dose from medical imaging (7). Additionally, the testes and ovaries are highly radiosensitive (8). 


\section{Method}

\section{Equipment}

Exposures were undertaken using a Wolverson Arcoma Arco Ceil general radiography system (Arcoma, Annavägen, Sweden) with a high frequency generator and VARIAN 130 HS X-ray tube. Total filtration was $3 \mathrm{~mm} \mathrm{Al}$ (inherent 0.5 , added $2.5 \mathrm{~mm}$ aluminium). X-ray tube quality control results fell within manufacturer tolerances. A calibrated Unfors Mult-O-Meter 401 (Billdal, Sweden) was used for measuring dose profiles from anode to cathode; it was also used to calibrate the TLDs.

A CIRS ATOM dosimetry adult phantom model 701-B was used (9) for direct dose measurements. The phantom consists of 39 contiguous sections of differing density epoxy resin. Two TLD chips were placed into each testicle and two into each ovary within predefined phantom holes.

A Harshaw 3500 TLD reader (Thermo Scientific, USA) was used to read the exposed TLD chips. High sensitivity LiF Mg,Cu (P-100H) TLDs were used. Prior to exposure, TLD quality control tests were conducted $(10,11)$. TLDs were grouped into batches of similar response in order to have homogenous groups. Any TLD that deviated greatly (>1.5 \% SD) from group mean was removed. Linearity of TLDs was tested over a range of doses; good correlation was found $\left(R^{2}=0.994\right)$. TLD reliability was tested, confirming high consistency (consistency coefficient $=0.99-1.00$ (intraclass correlation)). Linear regression forced through zero was used to determine the TLD calibration factor. To minimise residual dose from previous exposures, TLDs were annealed at $240 \mathrm{C}^{\circ}$ for $10 \mathrm{~min}$ then cooled to room temperature as per manufacturer recommendations. TLD accuracy was estimated to be less than $\pm 10 \%$. Five TLDs were used for background radiation dose correction.

\section{Data acquisition}

A dose profile, at $80 \mathrm{kVp}$ and $20 \mathrm{mAs}$, from the anode to cathode was plotted at $2 \mathrm{~cm}$ intervals (Figure 1) to determine the $\mathrm{x}$-ray beam intensity variation for the Wolverson Arcoma Arco Ceil general radiography system used in this study. This measurement was repeated with 4 SIDs $(105,110,115,120 \mathrm{~cm})$. Throughout this experiment the X-ray field size was maintained at $35 \times 43 \mathrm{~cm}$. 


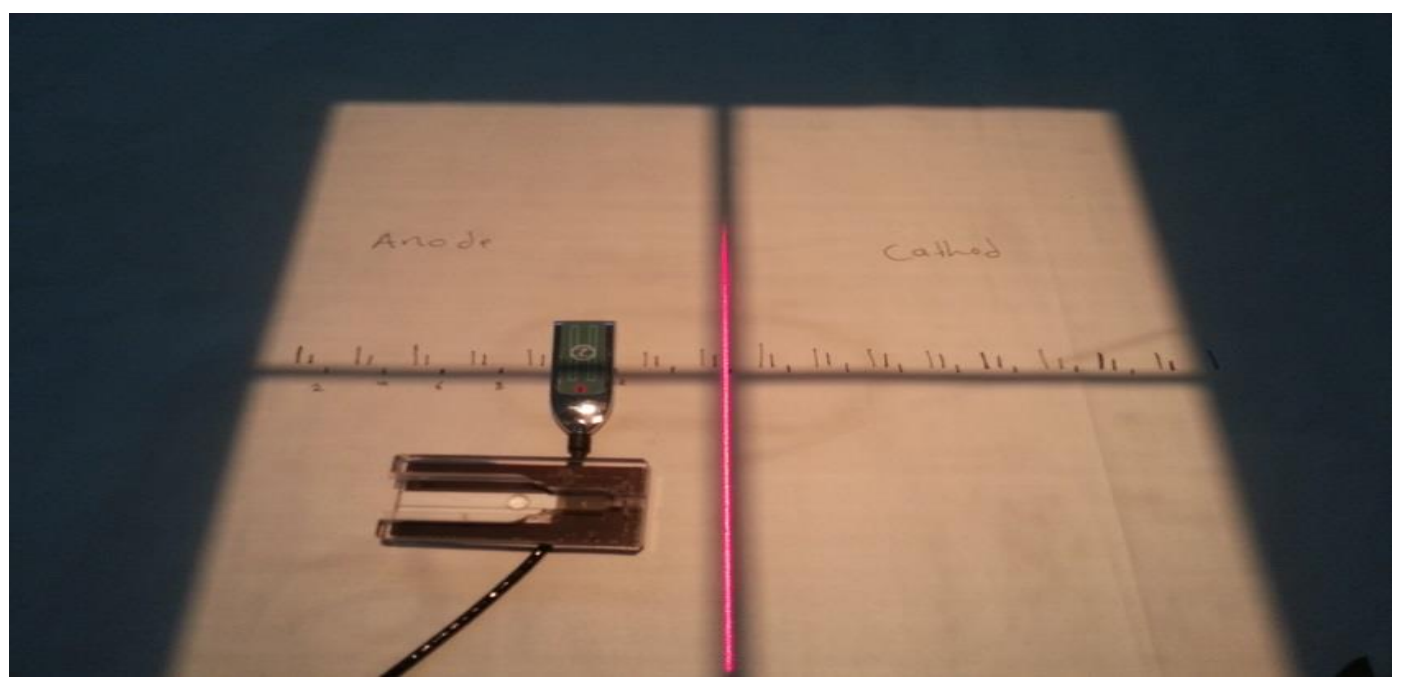

Figure 1. Experimental setup for measuring the dose profile

Next, the ATOM phantom was positioned for an AP pelvis projection (12). Collimation was set to $35 \times 43 \mathrm{~cm}$ at the image receptor surface and kept constant for all exposures. A factorial design was adopted to generate a range of $k V p$, mAs and SID combinations (13). This was based on the factorial formula $\mathrm{k}^{\mathrm{n}}$, where $\mathrm{n}$ refers to number of acquisition factors (e.g $\mathrm{kVp}$ ) and $\mathrm{k}$ refers to number of levels for each acquisition factor. Three factors were used (kVp, mAs and SID) and 4 levels for each (i.e. 70, 75, 80 and 85 kVp; 18, 22, 27 and 32 mAs; and 105, 110, 115 and $120 \mathrm{~cm}$ SID). This yielded 64 combinations. These acquisition factors are typical of those used in practice and also reported into the literature $(14,15)$.

A total of 64 exposures were repeated for each of the two phantom orientations: feet toward the anode; feet toward cathode. For each set of acquisition factors three exposures were made. These were averaged to minimise random error. Using TLDs the mean absorbed doses were calculated for both the testes and ovaries. 


\section{$\underline{\text { Results }}$}

The absorbed radiation dose, across all 4 SIDs, from anode to cathode is indicated in Table 1.

Table 1. Radiation dose profile (mGy) along the anode-cathode axis for the range of SIDs.

\begin{tabular}{|c|c|c|c|c|c|}
\hline \multirow{2}{*}{$\begin{array}{l}\text { Anode/Cathode } \\
\text { relationship }\end{array}$} & \multirow{2}{*}{$\begin{array}{c}\text { Distance } \\
\text { interval }(\mathrm{cm})\end{array}$} & \multicolumn{4}{|c|}{ Dose (mGy) } \\
\hline & & SID $105 \mathrm{~cm}$ & SID $110 \mathrm{~cm}$ & SID $115 \mathrm{~cm}$ & SID $120 \mathrm{~cm}$ \\
\hline \multirow{8}{*}{ Towards anode } & $-16 \mathrm{~cm}$ & 0.601 & 0.556 & 0.508 & 0.494 \\
\hline & $-14 \mathrm{~cm}$ & 0.702 & 0.610 & 0.556 & 0.526 \\
\hline & $-12 \mathrm{~cm}$ & 0.746 & 0.660 & 0.594 & 0.559 \\
\hline & $-10 \mathrm{~cm}$ & 0.794 & 0.708 & 0.630 & 0.585 \\
\hline & $-8 \mathrm{~cm}$ & 0.833 & 0.740 & 0.655 & 0.610 \\
\hline & $-6 \mathrm{~cm}$ & 0.865 & 0.771 & 0.686 & 0.628 \\
\hline & $-4 \mathrm{~cm}$ & 0.887 & 0.796 & 0.701 & 0.646 \\
\hline & $-2 \mathrm{~cm}$ & 0.908 & 0.815 & 0.724 & 0.660 \\
\hline $\begin{array}{l}\text { Central ray } \\
\text { (midway between } \\
\text { cathode and } \\
\text { anode) }\end{array}$ & Centre ray & 0.935 & 0.834 & 0.738 & 0.676 \\
\hline \multirow{8}{*}{ Towards cathode } & $+2 \mathrm{~cm}$ & 0.942 & 0.848 & 0.749 & 0.691 \\
\hline & $+4 \mathrm{~cm}$ & 0.954 & 0.857 & 0.757 & 0.697 \\
\hline & $+6 \mathrm{~cm}$ & 0.958 & 0.860 & 0.765 & 0.702 \\
\hline & $+8 \mathrm{~cm}$ & 0.957 & 0.862 & 0.767 & 0.702 \\
\hline & $+10 \mathrm{~cm}$ & 0.947 & 0.863 & 0.765 & 0.702 \\
\hline & $+12 \mathrm{~cm}$ & 0.939 & 0.854 & 0.764 & 0.695 \\
\hline & $+14 \mathrm{~cm}$ & 0.937 & 0.849 & 0.754 & 0.660 \\
\hline & $+16 \mathrm{~cm}$ & 0.935 & 0.836 & 0.742 & 0.633 \\
\hline
\end{tabular}

From Table 1 it can be seen that that radiation dose decreases towards the anode and increases towards the cathode. When mAs and kVp remain constant, as SID increases the dose radiation decreases in accordance with the inverse square law. Percentage dose reduction, for all SIDs, ranged from 27 to $36 \%$.

In order to demonstrate the percentage change in dose across the anode-cathode axis the interval ratio (difference in the measured dose between the cathode/anode; Table 2) was calculated using the following formula:

Percentage change $=\left(X_{i}-X_{0} / X_{0}\right) \times 100$ 
Where $X_{i}$ represents the high dose (cathode side) and $X_{0}$ represents the lower dose on the anode side. From table 2, it is clear that the percentage change at the extremes were greater than $20 \%$.

\begin{tabular}{|c|c|c|c|c|}
\hline \multirow[b]{2}{*}{$\begin{array}{l}\text { Interval Ratio } \\
\text { (Cathode/anode) }\end{array}$} & \multicolumn{4}{|c|}{ Change (\%) } \\
\hline & $105 \mathrm{~cm}$ & $110 \mathrm{~cm}$ & $115 \mathrm{~cm}$ & $120 \mathrm{~cm}$ \\
\hline$+16 /-16$ & 36 & 34 & 32 & 22 \\
\hline$+14 /-14$ & 25 & 28 & 26 & 20 \\
\hline$+12 /-12$ & 20 & 23 & 22 & 19 \\
\hline$+10 /-10$ & 16 & 18 & 18 & 16 \\
\hline$+8 /-8$ & 13 & 14 & 13 & 13 \\
\hline$+6 /-6$ & 9 & 10 & 10 & 11 \\
\hline$+4 /-4$ & 7 & 7 & 7 & 7 \\
\hline$+2 /-2$ & 3 & 4 & 3 & 4 \\
\hline
\end{tabular}

The radiation dose received by the testes and ovaries are shown in Figure 2 (A, B, C and D). Figure $2 \mathrm{~A}$ and $\mathrm{B}$ illustrate the gonad dose with the feet towards the cathode; Figure $2 \mathrm{C}$ and D illustrate the gonad dose with feet towards the anode. 
Figure 2. Gonad dose with the feet orientated towards the cathode (A, B) and with the feet placed towards the anode $(\mathrm{C}, \mathrm{D})$

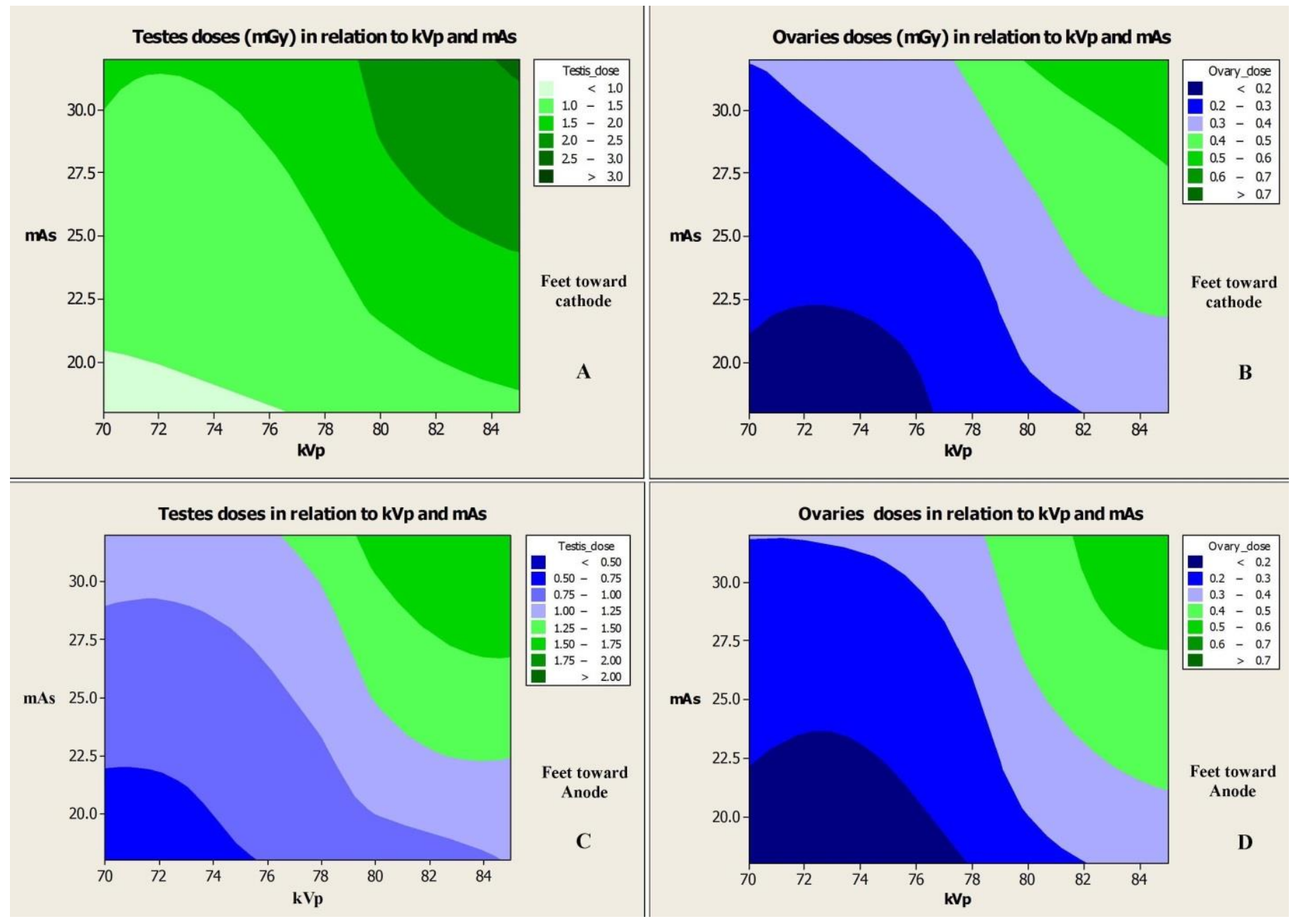

For testicular dose, there is a significant difference between orientations: mean 1.1mGy, SD 0.38 , with feet towards anode; and mean $1.60 \mathrm{mGy}$, SD 0.59, with feet towards cathode $(P<0.001, T$ Test $)$. No statistically significant difference was found for female gonad dose $(P>$ 0.05 ) between the two orientations.

As $\mathrm{kVp}$ and $\mathrm{mAs}$ increase so does testicular and ovarian dose; as SID increases testicular and ovarian dose decreases, see Figure $3(A, B, C$ and $D)$. Analysis of variance indicated that $k V p$, $m A s$ and SID have a significant effect on testicular and ovarian doses $(P<0.001)$, for both phantom orientations. 
Figure 3 (A, B, C and D): Demonstrates testicular and ovarian doses (mGy) when kVp, mAs and SID are increased for both phantom orientations. The horizontal lines represent mean dose values in each case.
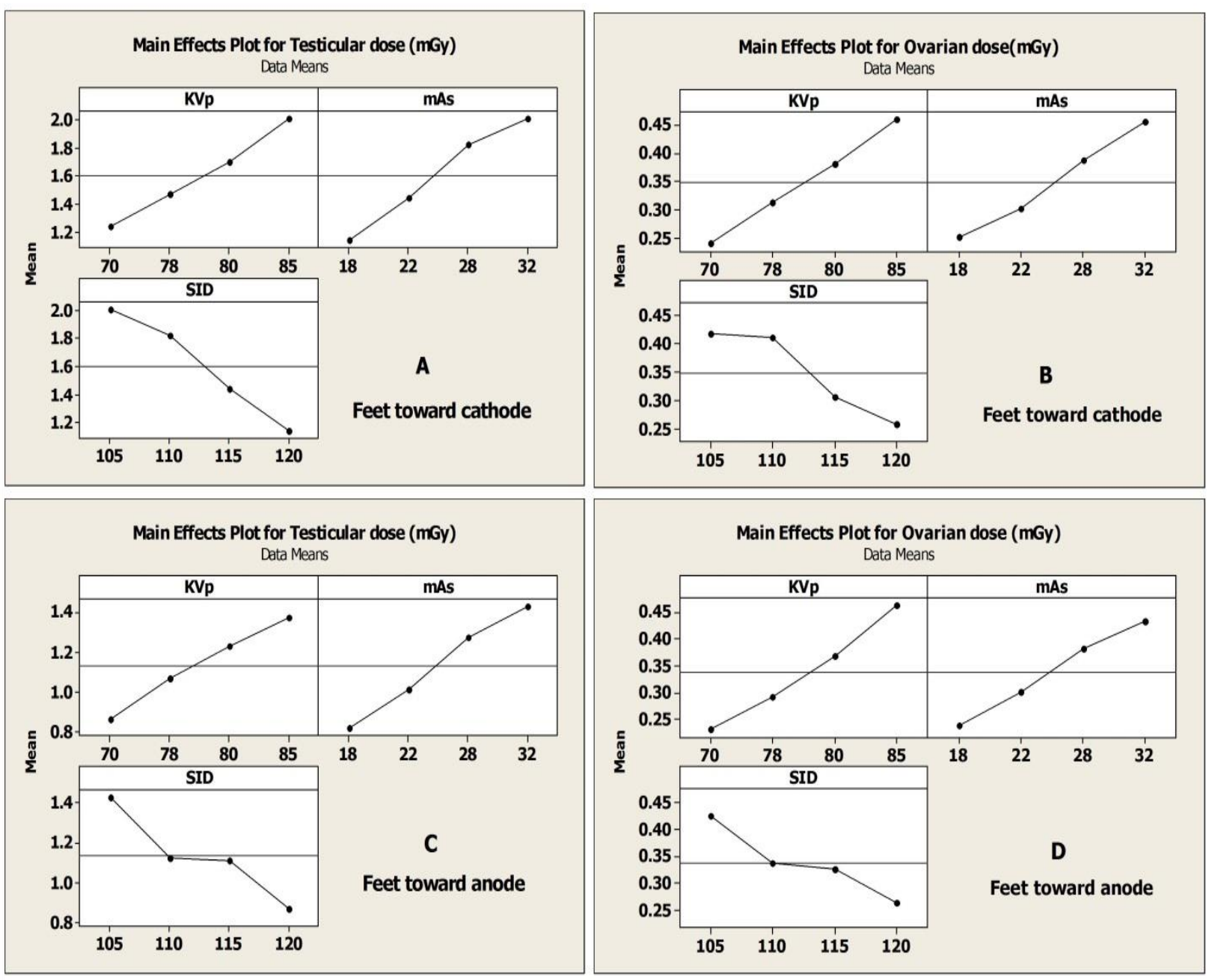

\section{$\underline{\text { Discussion }}$}

The dose profile data reported in Table 1 and 2 confirm previous findings (e.g. Bushong, 2013, Fung \& Gilboy, 2000 and Mearon \& Brennan, 2006), with the dose reducing from anode to cathode. For testes, the dose is significantly lower $(\mathrm{P}<0.001)$ with the feet towards anode. For ovaries, there is no statistical difference between orientations $(P>0.05)$. This might be explained by organs sited nearer the extreme edge of the un-collimated radiation field are likely to benefit more from the anode heel effect; given the testes are located further away from the central ray and at the edge of the field the impact of the anode heel effect will be higher. The ovaries are located nearer to the central ray, so the heel effect will be lower. 
The testicular doses in our study are similar to those reported by Fung and Gilboy (2000) (3), in their AP and lateral lumbar spine work. However our findings are at variance in regards of the ovaries; Fung and Gilboy (2000) (3) found significant differences in ovarian doses and attributed this to the anode heel effect. A possible explanation for this difference might be that during AP pelvic radiography the ovaries are located on or close to the central ray and, therefore, do not gain as much benefit from the anode heel effect.

The effect of increasing $k V p$ on ovarian dose was higher when compared with $m A s$. The reason for this could be related to ovarian depth within the abdomen; increasing beam intensity (mAs) is less effective at increasing dose compared with increasing the beam penetrating power (kVp). The effect of the SID was similar for ovarian and testicular doses for both orientations.

It is often the case that patients are positioned with their feet placed towards the cathode where the dose is high $(5,16)$. From our data it is clear that to minimise dose to testes the feet should be placed towards the anode. Also for ease in positioning from a practical stand point it would be sensible for males and females to be positioned with feet towards the anode.

Further work is required to consider the effect of the anode heel on other organs in the radiation field when undertaking AP pelvis radiography, especially those that are classed as highly radiosensitive organs such as those with tissue weighting factors of 0.12 e.g. colon (8).

\section{Conclusion}

For AP pelvis radiography, the anode heel effect can be utilised to significantly reduce testicular dose by placing the feet towards the anode. The anode heel effect has no impact on ovarian dose. For the sake of consistency, for males and females, the feet should be placed towards the anode. Further dose reduction can be achieved to the tests and ovaries by manipulating kVp, $\mathrm{mAs}$ and SID ; however for ovaries $\mathrm{kVp}$ has the largest impact whereas $\mathrm{mAs}$ has the largest impact for ovaries. 


\section{$\underline{\text { Reference }}$}

1. Sherer MAS, Visconti PJ, Ritenour ER, Haynes KW. Radiation protection seventh edition in medical radiography. 7 ed. Phalidelphia: Mosby; 2014.

2. Bushong SC. Radiologic science for technologists physics, biology, and protection. 3 ed. Missouri: Mosby; 2013.

3. Fung KLL, Gilboy WB. Anode heel effect" on patient dose in lumbar spine radiography. British journal of radiology. 2000;73(2000):531-6.

4. Mearon T, Brennan PC, editors. Anode heel affect in thoracic radiology: a visual grading analysis. Medical Imaging 2006: Physics of Medical Imaging; 2006; San Diego, CA.: SPIE; 2006.

5. Carroll QB. Radiography in the digital age physics-exposure- radiation biology. USA: CHARLES C THOMAS; 2011.

6. Graham DT, Cloke P, Vosper M. Principles and Applications of Radiological Physics. 6 ed. Livingstone: Churchill; 2011.

7. Hart D, Wall BF, Hillier MC, Shrimpton PC. Frequency and collective dose for medical and dental X-ray examinations in the UK. Chilton: Health Protection Agency 2010 Contract No.: HPA-CRCE-012.

8. ICRP. The 2007 Recommendations of the International Commission on Radiological Protection.ICRP Publication 103. Annals of ICRP. 2007;37(2-4):1-332.

9. CIRS. ATOM dosimetry phantom :Adult male phantom model number 701-D appendix 5. Virginia, USA: CIRS, Inc2013.

10. Rivera T. Thermoluminescence in medical dosimetry. Applied Radiationandlsotopes. 2012;71(Supplement):30-4.

11. Tootell AK, Szczepura KR, Hogg P. Optimising the number of thermoluminescent dosimeters required for the measurement of effective dose for computed tomography attenuation correction data in SPECT/CT myocardial perfusion imaging. Radiography. 2013;19(1):42-7.

12. Whitley AS, Sloane C, Hoadley G, Moore AD, Alsop CW. Clark's positioning in radiography. 12 ed. London: Hodder Arnold.; 2005.

13. Montgomery DC. Design and Analysis of Experiments. USA: John Wiley \& Sons; 2013.

14. Carver B, Carver B. Medical Imaging Techniques, Reflection \& Evaluation. 2 ed. Edinburgh: Churchill Livingstone; 2012.

15. Bontrager KL, Lampignano JP. Textbook of radiographic positioning and related anatomy. 8 ed. Missouri: Mosby; 2014. 
16. Harding L, Manning-Stanley AS, Evans P, Taylor EM, Charnock P, England A. Optimum patient orientation for pelvic and hip radiography: A randomised trial. radiography. 2014;20(1):22-32 